\title{
AMMONIUM SULFATE CRYSTALLIZATION IN ANDERSEN CASCADE IMPACTOR SAMPLES
}

\author{
A. Nelson Dingle and Bhanuprasad M. Joshi \\ Department of Atmospheric and Oceanic Sciences, The University of Michigan, \\ Ann Arbor, Michigan 48104, U.S.A.
}

(First received 20 June 1973 and in final form 1 March 1974)

\begin{abstract}
Meteorologists are accustomed to the atmospheric phase changes of water. It is observed that phase changes ending with crystallization and crystal growth of $\left(\mathrm{NH}_{4}\right)_{2} \mathrm{SO}_{4}$ take place in Andersen Samplers used to collect size-stratified samples of airborne particles. It is not at this point clear whether preformed $\left(\mathrm{NH}_{4}\right)_{2} \mathrm{SO}_{4}$ crystals of small size are involved, although this is likely, but the cascade impaction processes evidently play a rôle in generating large $\left(\mathrm{NH}_{4}\right)_{2} \mathrm{SO}_{4}$ crystals on the last few stages of these samplers.
\end{abstract}

\section{INTRODUCTION}

Ammonium sulfate is one of the important constituents of continental aerosols (Junge, 1954; Eggleton, 1964). Garland (1969) has studied the effect of ammonium sulfate particles on visibility. Healy et al. (1970) have reported the formation of ammonium sulfate and removal of ammonia from the troposphere. The present study deals with the formation and growth of ammonium sulfate crystals during sampling with an Andersen sampler. These cascade type impactors have been widely used for field collection of airborne particles in size-stratified samples. By means of various analytical techniques including atomic absorption (Nifong, 1970), neutron activation analysis (Rahn, 1971) and anodic stripping voltametry (Harrison, 1970), some 50 chemical elements have been identified, measured and classified according to size distribution type in such samples. For the purposes of cloud physics, and the evaluation of air cleansing by precipitation, among others, the problem remains to determine the exact molecular nature of the airborne particles. McCrone et al. (1967) have given about 400 photomicrographs of various particles but nothing is yet reported about the formation and growth of crystalline particles during the sampling of aerosols.

The manufacturer's calibration for the Andersen sampler is given in Table 1. These calibration data are derived by means of laboratory tests using spherical particles of unit density and a controlled flow rate of $1 \mathrm{ft}^{3} \mathrm{~min}^{-1}$. In practice it is observed that the classification of airborne particles is less sharply defined because of variable shapes and densities of the particles, and frequently because of difficulty in maintaining the specified flow rate throughout the necessary sampling period.

\section{EXPERIMENTAL}

\section{Sampling}

The Andersen sampler (Model 0203) modified by the addition of a seventh impaction stage was used to collect and separate airborne particles according to their sizes. During sampling, the sampler was covered with an inverted petri dish to prevent rain water or snow from entering into the sampler. Most sampling was done on the roof of East Engineering building ( $\mathrm{ca} .60 \mathrm{ft}, 18.3 \mathrm{~m}$, above ground level). 
Table 1. Andersen sampler: particle size distribution

\begin{tabular}{|c|c|c|c|c|c|}
\hline Stage & $\begin{array}{l}\text { No. of } \\
\text { jets }\end{array}$ & $\begin{array}{c}\text { Radius } \\
\text { of jet* } \\
\left(\times 10^{* 2} \mathrm{~cm}\right)\end{array}$ & $\begin{array}{l}\text { Jet } \\
\text { velocity* } \\
\left(\mathrm{cm} \mathrm{s} \mathrm{s}^{-1}\right)\end{array}$ & $\begin{array}{c}\text { Range of } \\
\text { particle } \\
\text { radius given } \\
\left(\times 10^{-4} \mathrm{~cm}\right)\end{array}$ & $\begin{array}{c}\text { Range of } \\
\text { particle } \\
\text { radius obseryed } \\
\left(\times 10^{-4} \mathrm{~cm}\right)\end{array}$ \\
\hline 1 & 400 & 5.91 & 1079 & $>4.6$ & 5.130 \\
\hline 2 & 400 & 4.57 & 179.5 & 2.754 .6 & 1.560 \\
\hline 3 & 400 & 3,56 & 296.9 & 1.052 .75 & 1.0 .2 .5 \\
\hline 4 & 400 & 2.67 & 527.6 & 10165 & 0510 \\
\hline 5 & 400 & 1.71 & 1277.7 & $0.5-1.0$ & $\begin{array}{c}0.510 \\
2.550)\end{array}$ \\
\hline 6 & 400 & 1.27 & 2328.7 & -0.5 & $\begin{array}{l}10.350 .5 \\
(2.515)\end{array}$ \\
\hline 7 & 216 & 1.27 & 4312.4 & $<0.5$ & $\begin{array}{r}0.25 \cdots(0,5 \\
(420)\end{array}$ \\
\hline
\end{tabular}

* The values are given by the manufacturer (Andersen samplers, 1968).

F For spherical particles of unit density or other particles of aerodynamically equivalent dimensions. The size limits indicate the approx. 50 per cent of points.

¥ Values are computed from observation under optical microscope. Values in parenthesis for stages 57 corresponds to crystalline particles.

Samples of aerosols have been collected by different investigators from this department, (Nifong, 1970; Harrison, 1970; Rahn, 1971) for 8-20 h and, also up to 6 days or more time, for various methods of chemical analysis, which did not include inspection of samples under microscope. In our laboratory, sample collections were made for varying periods of time from 16 to $120 \mathrm{~h}$. These samples were observed under a microscope and typical pho-

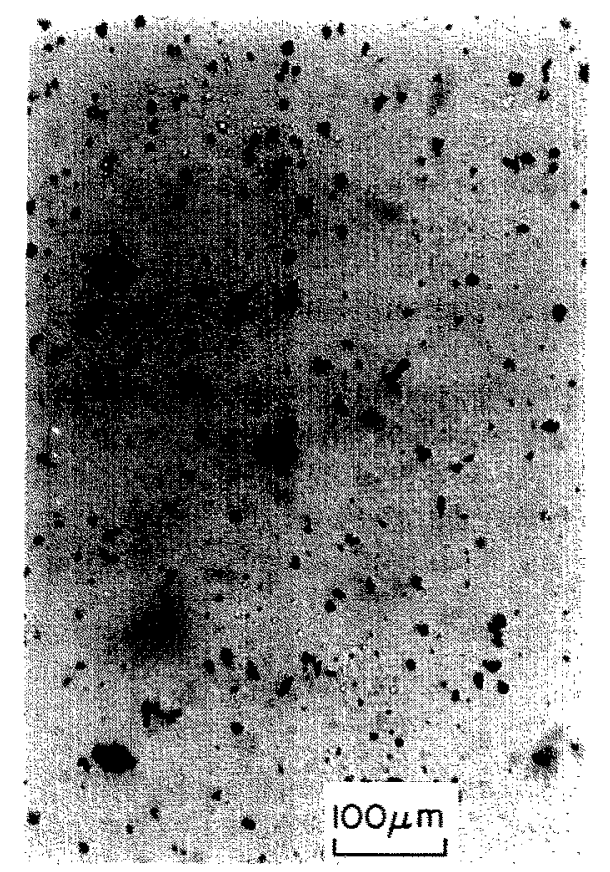

Fig. 1. Particles collected on stage 1, also showing plant pollens (sphericalf at the center of photograph. 
tomicrographs are shown in Figs. 1-12. In broad terms, these figures show particles of decreasing size collected on the respective impaction plates of stages 1-6. However, some of the particles on the fifth, sixth and seventh stages were found to be much larger than was expected (see Table 1).

\section{Microscopic observation of particles on Andersen sampler}

Stage 1. The particles appeared dark when observed under transmitted light; however they were found to be of different colors in reflected light, such as white, yellow, green, blue and rarely dark brown and red. They seem to be dust particles consisting mainly of silica. They were found to be insoluble in water and dilute $(2 \mathrm{~N}) \mathrm{HCl}$. The particles vary from 5 to $13 \mu \mathrm{m}$ in radius, the average being about $7 \mu \mathrm{m}$. Some particles of flower pollen were also observed in this stage; they have a definite shape, whereas the other particles are of irregular shapes (Fig. 1).

Stages 2 and 3 . The particles collected on these impaction stages were found to be more or less identical in appearance to those of stage 1 . They were slightly smaller in size and much greater in number, the latter being shown by their closeness on the sampling surface. The particle sizes of stage 2 range from about $1.5-6.0 \mu \mathrm{m}$ in radius, the average being about $3.5 \mu \mathrm{m}$ (Fig. 2); those for stage 3 are from about $1.0-2.5 \mu \mathrm{m}$ in radius with an average of about $2 \mu \mathrm{m}$ (Fig. 3)

The particles of stages 4 and 5 were found to be lying too close to each other to identify them as separate particles. It was difficult to resolve them and study their shape by an optical microscope (Figs. 4 and 5). Under reflected light they appeared as an amorphous

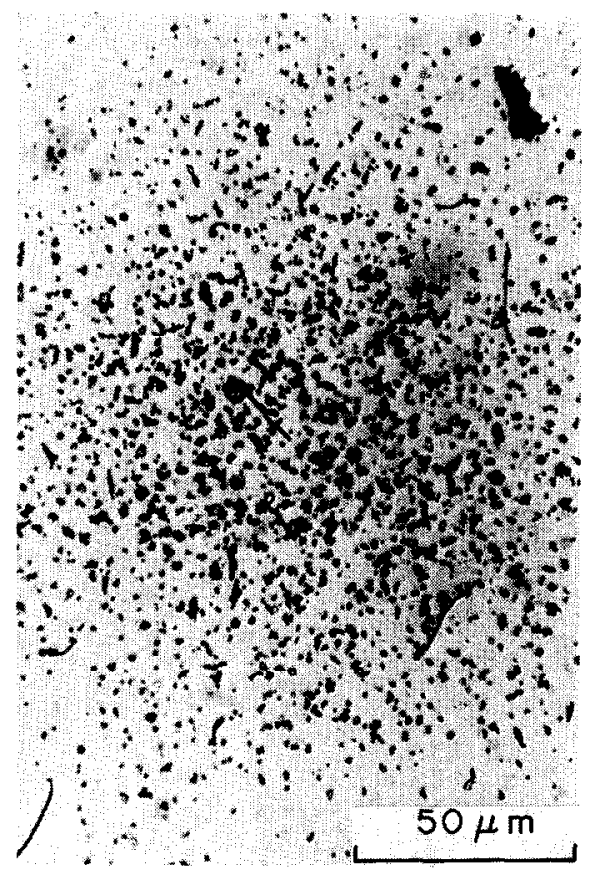

Fig. 2. Particles collected on stage 2. 


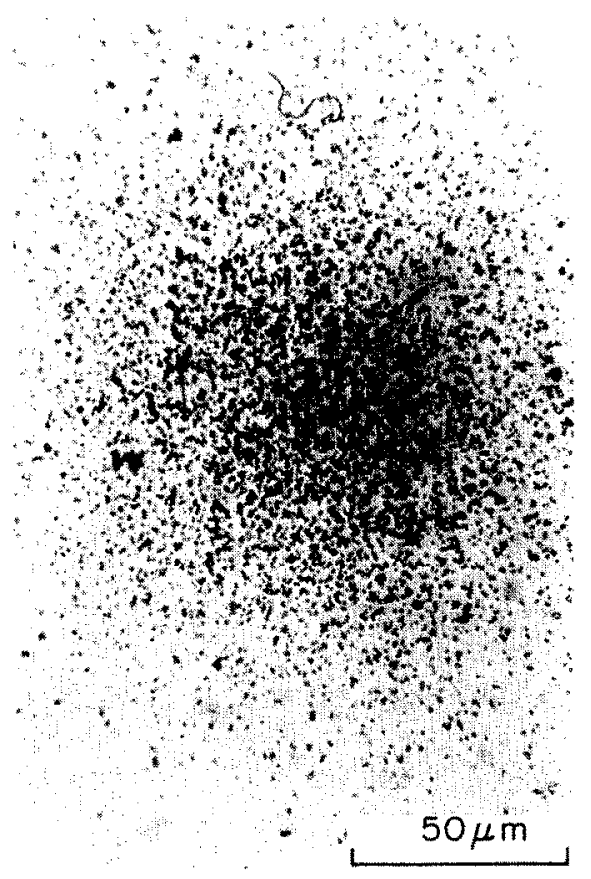

Fig. 3. Particles collected on stage 3.

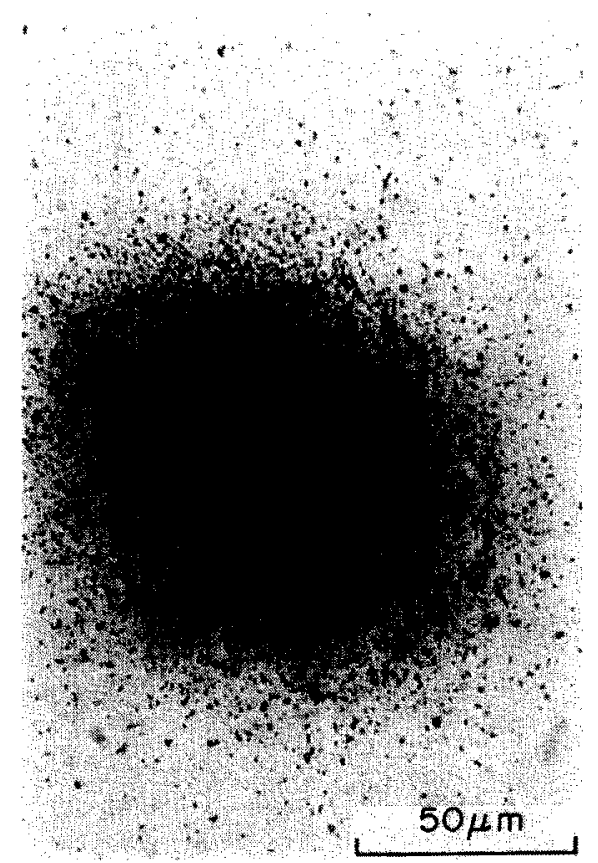

Fig. 4. Particles collected on stage 4. 


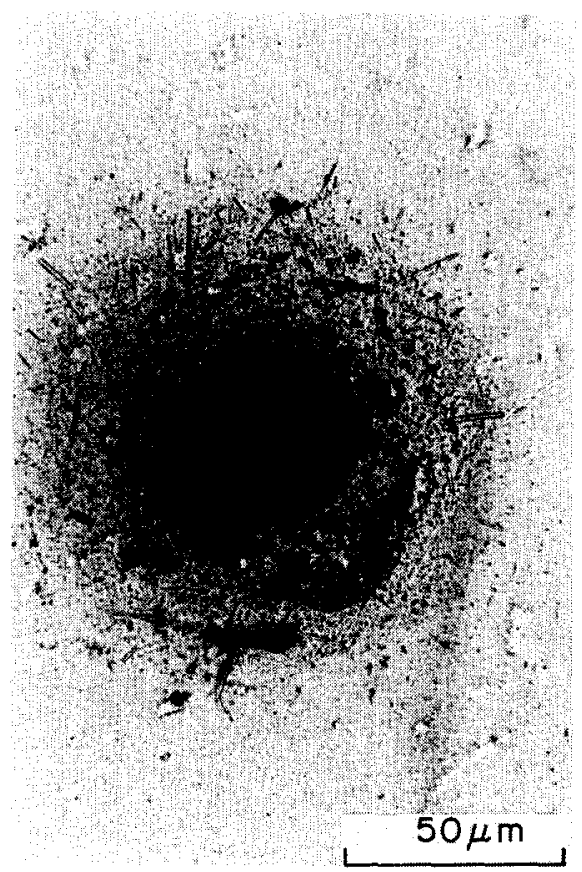

Fig. 5. Particles collected on stage 5 showing needle shaped crystalline particles.

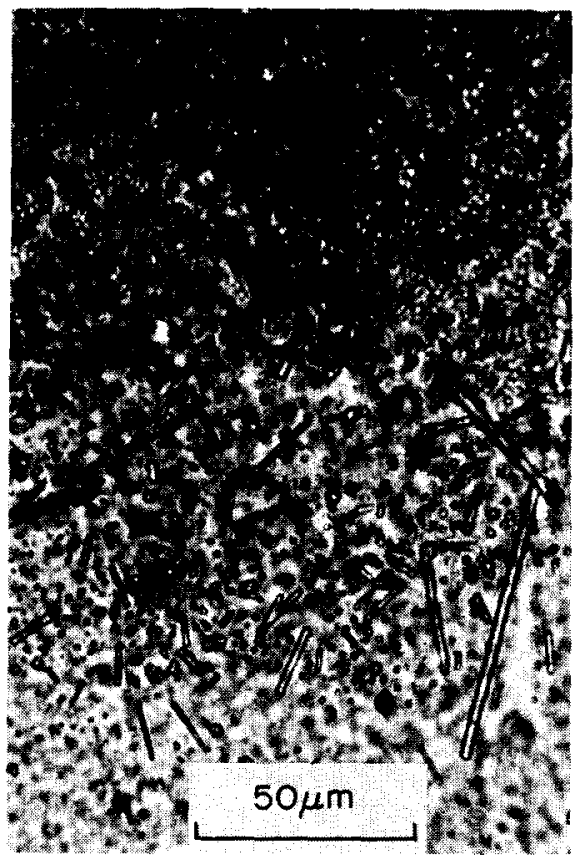

Fig. 6. Stage 5 further enlarged. 


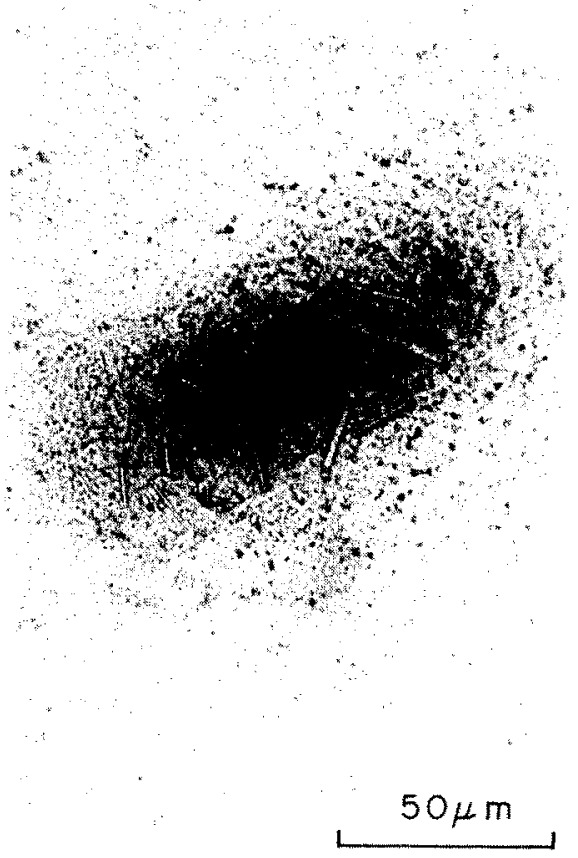

Fig. 7. Particles on stige 6.

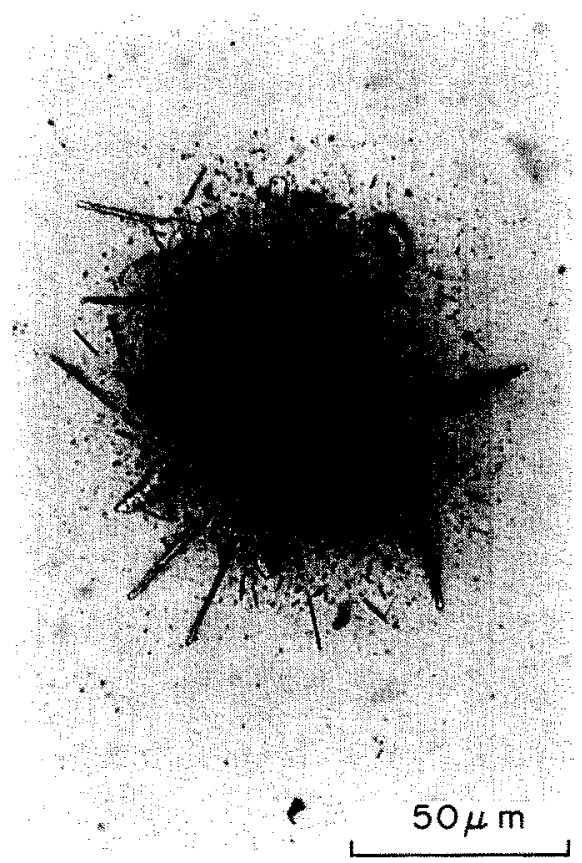

Fig. 8. Typical needle shaped erystals including some irregular shapes on stage 7. 


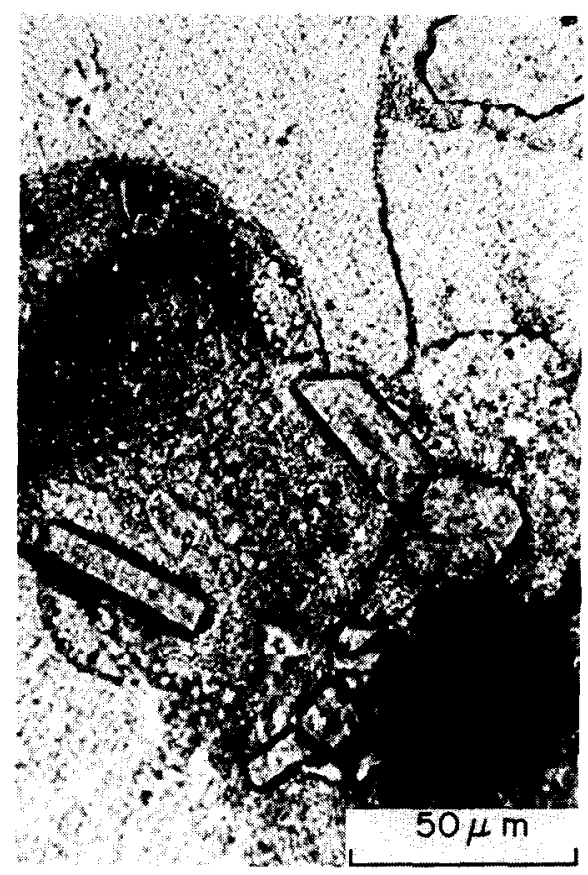

Fig. 9. Large crystals growing in a droplet on stage 7.

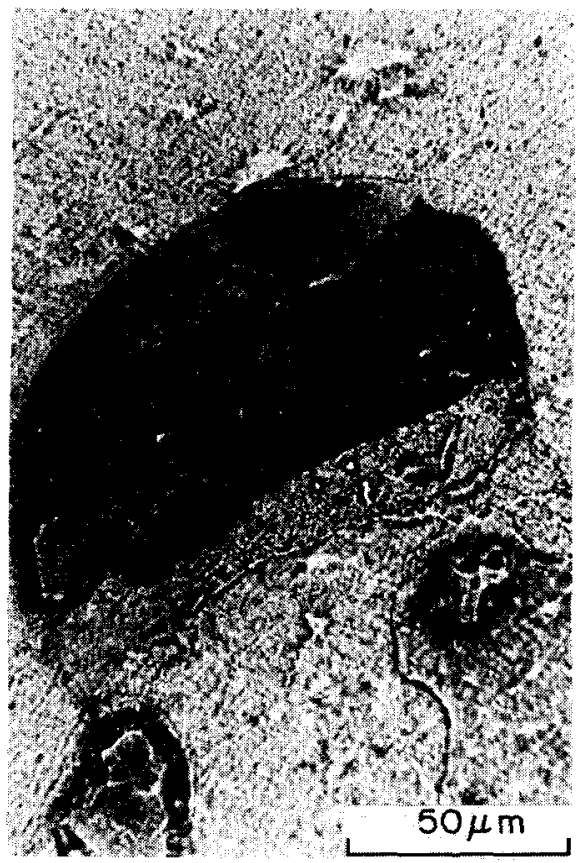

Fig. 10. A single large crystal growing in a droplet on stage 7 . 


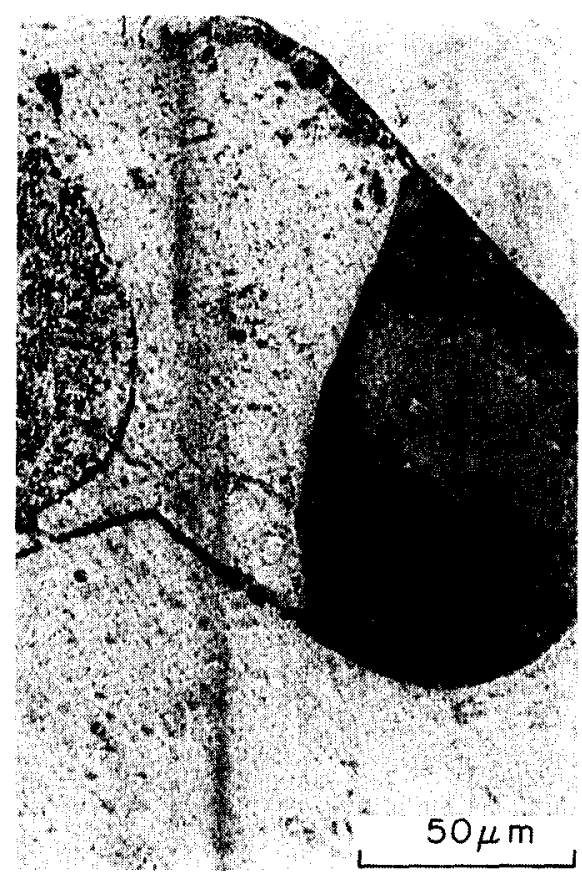

Fig. 11. Photograph showing a droplet formed. when the sampling was stopped immediately after rain. Stage 7.

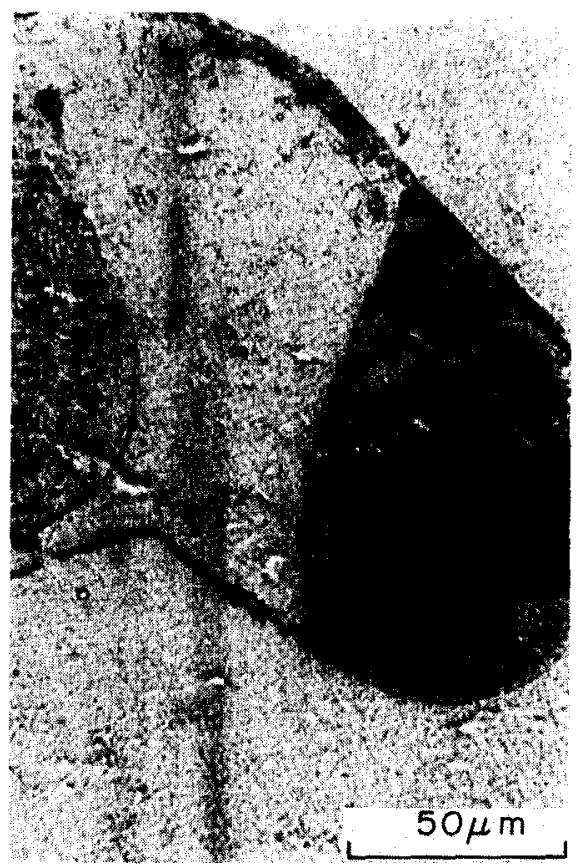

Fig. 12. Same droplet as in Fig. 11, photographs after 5 min showing rocrystallization from the droplet. 
opaque mass. However in stage 5 some needle-shaped crystalline particles were found. Their width was about 1-2 $\mu \mathrm{m}$ while the length was from 6 to $15 \mu \mathrm{m}$ (Figs. 5 and 6). These particles were found to be readily soluble in water and insoluble in alcohol. (Note, Table 1 , that the crystals tended to increase in size with increasing stage number).

In stage 6 (Fig. 7) the particles were found to be partly (10-40 per cent) crystalline and partly (60-90 per cent) small and opaque (carbon, silica, etc).

The samples on stage 7 (Fig. 8-10) were found to contain large crystals of various shapes; cubic, orthorhombic, acicular and irregular. These were colorless and readily soluble in water and insoluble in alcohol. They were observed to increase in size as the sampling time was increased, and were frequently larger than the dia. of the air jet openings of this stage $(25 \mu \mathrm{m})$. When, immediately after a rainfall the sampling was stopped and the sample sheet was observed under a microscope, we could observe a droplet slowly evaporating and small crystals appearing in that place. (See Figs. 11 and 12.)

\section{$X$-ray crystallography}

The crystalline particles from the samples (stages 6 and 7) were separated from the polyethylene film substrate and placed into a capillary tube for X-ray powder diffraction analysis. The quantity of sample was very small $[\sim 0.1 \mathrm{mg}]$ so that it could not be made into a fine powder; and hence the capillary was rotated during the experiment to obtain a uniform diffraction pattern of smooth lines rather than separate spots on the photographic film.

Under these circumstances the resolution of the diffraction lines is less than ideal; as a consequence lines 25 and 26 (Table 2) were seen as one line in the sample analysis. Twenty-five significant diffraction lines were recorded out of which 22 lines agreed within 2 per cent with the diffraction lines given for $\left(\mathrm{NH}_{4}\right)_{2} \mathrm{SO}_{4}$ (JCPDS, 1972). Actually there are 30 diffraction lines for $\left(\mathrm{NH}_{4}\right) \mathrm{SO}_{4}$ between 5.31 and $1.945 \AA$, but eight lines are of intensity $\leq 3$ per cent of the principal line and hence these eight lines were not significantly noticed in the sample. The additional three lines observed in the diffraction pattern of the sample were of about 30 per cent intensity and could not be attributed to any reported compound. They may have arisen from some impurities carried with the crystalline particles during mechanical separation. The data of this experiment are given in Table 2.

\section{Chemical analysis}

The molecular composition of these crystalline particles was further confirmed by chemical analysis to be that of ammonium sulfate. For this experiment, the sampler was operated continuously for $50 \mathrm{~h}$, accumulating about $400 \mu \mathrm{g}$ of particles on each stage. The crystals were separated from the sample by dissolving in distilled water. The solution was analyzed for $\mathrm{NH}_{4}^{+}$by colorimetry (Weatherburn, 1967) and for $\mathrm{SO}_{4}^{2-}$ by the barium chloranilate (Gales et al., 1968) method.

Possible combinations of $\mathrm{NH}_{4}^{+}$and $\mathrm{SO}_{4}^{2-}$ ions include $\mathrm{NH}_{4} \mathrm{HSO}_{4}$ and $\left(\mathrm{NH}_{4}\right)_{2} \mathrm{~S}_{2} \mathrm{O}_{8}$ in addition to $\left(\mathrm{NH}_{4}\right)_{2} \mathrm{SO}_{4}$. Quantitative chemical analysis yielded the value of 0.38 for the $\mathrm{NH}_{4}: \mathrm{SO}_{4}$ mass ratio. This mass ratio corresponds to the molecular formula $\left(\mathrm{NH}_{4}\right)_{2} \mathrm{SO}_{4}$ and can not result from any combination of the other molecular forms. The mass ratio is equal to 0.2 for $\mathrm{NH}_{4} \mathrm{HSO}_{4}$ and 0.19 for $\left(\mathrm{NH}_{4}\right)_{2} \mathrm{~S}_{2} \mathrm{O}_{8}$.

To study the distribution of ammonium sulfate on each stage, a separate experiment was carried out. The sampler was operated continuously for $72 \mathrm{~h}$. A representative fraction from each stage was selected and the particles were dissolved in water and analyzed as 
Table 2. X-ray powder dimaction data

\begin{tabular}{|c|c|c|c|c|}
\hline \multicolumn{3}{|c|}{$\left(\mathrm{NH}_{4}\right)_{2} \mathrm{SO}_{4}$ Standard* } & \multicolumn{2}{|c|}{ Sample } \\
\hline $\begin{array}{l}\text { Line } \\
\text { No. }\end{array}$ & $\begin{array}{l}\text { Inter planer spacings } \\
\qquad(\AA)\end{array}$ & $\begin{array}{c}\text { Relative } \\
\text { intensity } \\
(a)\end{array}$ & $\begin{array}{c}\text { Inter planer spacings } \\
(A)\end{array}$ & $\begin{array}{l}\text { Relative } \\
\text { intensity } \\
( \pm 5 \%)\end{array}$ \\
\hline 1 & 5.31 & 15 & 5.29 & 20 \\
\hline 2 & 5.22 & 30 & 5.19 & 30 \\
\hline 3 & 4.39 & 65 & 4.39 & 70 \\
\hline 4 & 4.33 & 100 & $4,3.3$ & 100 \\
\hline 5 & 3.89 & 35 & $3.8 \%$ & 40 \\
\hline 6 & 3.66 & $<1$ & & \\
\hline 7 & & & 3.42 & 30 \\
\hline 8 & 3.264 & $<1$ & & \\
\hline 9 & 3.227 & 1 & & \\
\hline 10 & 3.139 & .30 & 3.130 & 30 \\
\hline 11 & 3.122 & 25 & $3.11 x$ & 30 \\
\hline 12 & 3.055 & 55 & 3.048 & 50 \\
\hline 13 & & & 3.035 & 30 \\
\hline 14 & & & 3.006 & 30 \\
\hline 15 & 2.998 & 25 & 2990 & 30 \\
\hline 16 & 2.839 & 1 & & \\
\hline 17 & 2.782 & 3 & 2.773 & $<5$ \\
\hline 18 & 2.704 & 5 & 2.705 & 5 \\
\hline 19 & 2.655 & 13 & 3.646 & 10 \\
\hline 20 & 2.611 & 7 & 2604 & 5 \\
\hline 21 & 2.521 & 9 & 2.523 & 10 \\
\hline 22 & 2.476 & 3 & & \\
\hline 23 & 2.401 & 3 & 2.401 & $<5$ \\
\hline 24 & 2.374 & 3 & & \\
\hline 25 & 2.322 & 17 & 2.317 & 30 \\
\hline 26 & 2.317 & 20 & $2.317\}$ & $30\}$ \\
\hline 27 & 2.196 & 9 & 2.189 & 10 \\
\hline 28 & 2.168 & 15 & 2.168 & 10 \\
\hline 29 & 2093 & 5 & 2.089 & 5 \\
\hline 30 & 2062 & $<1$ & & \\
\hline .31 & 2005 & $<1$ & & \\
\hline 32 & 1.973 & 5 & 1.973 & 5 \\
\hline 33 & 1.945 & 5 & $1.944\}$ & 10 \\
\hline 34 & 1.942 & 5 & $1.944\}$ & 10 \\
\hline
\end{tabular}

* From JCPDS X-ray powder diffraction data File No. 10-343.

Note: Lines $6,8,9,16,22,24,30$ and 31 of $I / I_{1} \leq 3$ were too faint to observe in the sample spectrum. Line pairs $25-26$ and $33-34$ were observed as a single line in the sample spectrum because of the slightly poor resolution obtained with the larger size of the crystals. Lines 7.13.14 from the sample spectrum could not be attributed to any known compound. Line 7 seems to correspond with the principle line of $\mathrm{PbSiO}_{3}(3.34 \AA)$ however no other major lines of $\mathrm{PbSiO}_{3}$ were observed.

above for $\left(\mathrm{NH}_{4}\right)_{2} \mathrm{SO}_{4}$ content. Table 3 shows the amount of $\left(\mathrm{NH}_{4}\right)_{2} \mathrm{SO}_{4}$ collected on each stage, and also the percentage of the total $\left(\mathrm{NH}_{4}\right)_{2} \mathrm{SO}_{4}$ collected on each stage during the experiment.

These data indicate that about 95 per cent of the ammonium sulfate is collected on stages 5-7. According to Table 1, particles normally collected on these stages are smaller than $0.5 \mu \mathrm{m}$ in radius. It is not certain, because of the evident growth of $\left(\mathrm{NH}_{4}\right)_{2} \mathrm{SO}_{4}$ crystals, that the ammonium sulfate is deposited as particles. However Heard and Wiffen (1969), report a maximum radius for ammonium sulfate particles to he $0.5 \mu \mathrm{m}$, determined by means of electron microscopy on millipore filter samples. 
Table 3. Ammonium sulfate collected on various stages of Andersen sampler

\begin{tabular}{cccc}
\hline $\begin{array}{c}\text { Stage } \\
\text { No. }\end{array}$ & $\begin{array}{c}\left(\mathrm{NH}_{4}\right)_{2} \mathrm{SO}_{4} \\
(\mu \mathrm{g})\end{array}$ & $\begin{array}{c}\% \text { of total } \\
\left(\mathrm{NH}_{4}\right)_{2} \mathrm{SO}_{4} \\
\text { collected }\end{array}$ & $\begin{array}{c}\text { \% of }\left(\mathrm{NH}_{4}\right)_{2} \mathrm{SO}_{4} \\
\text { with respect to } \\
\text { total particles } \\
\text { on each stage }\end{array}$ \\
\hline 1 & 10 & $<1$ & 1.5 \\
2 & 12 & 1 & 1.5 \\
3 & 10 & $<1$ & 1.5 \\
4 & 30 & 2.6 & 5 \\
5 & 270 & 23 & 42 \\
6 & 400 & 34 & 56 \\
7 & 450 & 38 & 63 \\
\hline
\end{tabular}

\section{RESULTS AND DISCUSSION}

This finding (of Table 3) above indicate that ammonium sulfate particles should have been collected mainly on stages 5-7 of the Andersen sampler. The growth of large crystals may follow the small particle collection by other processes, e.g. solution and recrystallization. However two possible explanations can be put forward to the formation of these crystalline particles depending upon the microscopic observation and weather condition prevailing during sampling of aerosol.

1. Particles as seen on the photographs (Figs. 5-8) were collected when the r.h. was less than 40 per cent during the sample collection, and the time of sample collection was between 20 and $40 \mathrm{~h}$. The particles were of fine needle-like shape and might have formed by the direct interaction of the constituents $\left(\mathrm{NH}_{3}, \mathrm{H}_{2} \mathrm{O}, \mathrm{SO}_{2}, \mathrm{O}_{2}\right)$ upon the surface of other smaller particles. The total mechanism of this reaction is very complex; but from the thermodynamic data, the reaction between these constituents to form $\left(\mathrm{NH}_{4}\right)_{2} \mathrm{SO}_{4}$ has a very large equilibrium constant $\sim 10^{47}$.

2. Crystalline particles as seen on the photographs (Figs. 9-12) clearly appear to be forming from solution. This type of crystals was observed when there was r.h. of 50 per cent or more and possibly intermittent rain during the sampling time of more than $20 \mathrm{~h}$.

When the incoming air is very humid and/or contains very fine droplets, the collected particles of the ammonium sulfate dissolve and form a solution in a droplet form on the sampling spot; later on relatively dry air passed through the sampler, dries the droplet by evaporation and recrystallization into large crystals takes place. There is, in fact, a pressure drop of $\sim 65$ mbar and a temperature rise of $c a .0 .5-0.7^{\circ} \mathrm{C}$ from stages $1-7$. This creates a favorable condition for evaporation of water from the later stages where it may be initially deposited in droplet form.

Acknowledgements--The authors wish to thank Professor J. D. Hanawalt of Materials and Metallurgical Engineering for his valuable assistance in interpretation of diffraction lines obtained in the X-ray crystallography experiment. This rescarch has becn supported by the Earth Sciences Branch, Division of Biomedical and Environmental Research, U.S. Atomic Energy Commission, under Contract No. AT (11-1)-1407.

Andersen samplers (1968) Utah; now made by 2000 Inc., P.O. Box 7500, Utah.

Eggleton A.E. J. (1969) The chemical composition of atmospheric aerosols on Tees-side and its relation to visibility. Atmospheric Environment 3, 355-372.

Gales M. E., Jr., Kaylor W. H. and Longbottom J. E. (1968) Determination of sulfate by automatic colorimetric analysis. Analyst 93, 97-100. 
Garland J. A. (1969) Condensation on ammonium sultate particles and its eflect on visibility. Atmospheric Environment 3, 347-354.

Harrison P. R. (1970) Areawide distribution of lead. copper. Ladmium and bismuth in atmospheric particles in Chicago and Northwest Indiana: A multi-sample application and anodic stripping voltammetry. University of Michigan Ph.D. Thesis.

Healy T. V., MacKay H. A. C., Pilbeam A. and Scargill D. (1970) Ammonia and ammonium sulfate in the troposphere over the United Kingdom. J. geophys. Res. 75, 2317.2321.

Heard M. J. and Wiffen R. D. (1969) Electron microscopy of natural aterosols and the identification of particulate ammonium sulfate. Atmospheric Encironment 3, $337,340$.

Joint Committee on Powder Diffraction Standards (1972) Index to the powder diffraction file. Prepared and published by JCPDS, 1601 Parklane, Swarthmore. Pennsylvania.

Junge C. (1954) The chemical composition of atmospheric atrosols. I. Measurement at Round Hill field station June-July, 1953. J. Met. 11, 323-333.

Junge C. E. and Ryan T. G. (1958) Study of the $\mathrm{SO}_{2}$ oxidation in solution and its role in atmospheric chemistry Q.J.R. met. Soc. 84, 46-55.

McCrone W. C., Draftz R. G. and Delly J. G. (1967) The Particle Ath. Ann Arbor. Michigan.

Nifong G. D. (1970) Particle size distribution of trace elements in pollution aerosols. University of Michigan Ph.D. thesis.

Rahn K.A.(1971) Sources of trace clements in acrosols. An approach to clean air. Lniversity of Michigan Ph.D. Thesis.

Weatherburn M. W. (1967) Phenol hypochlorite reaction for determination of ammonia. Anal. Chem. 39, 971 -974 .

Van den Heuvel A. P. and Mason B. J. (1963) The formation of ammonium sulfate in water droplets exposed to gaseous sulfur dioxide and ammonia. Q.J. R. mot. Soc. 89, 271275. 